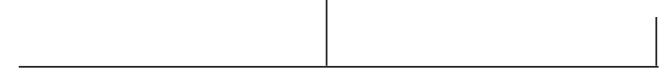

Rev. Latinoam. Psicopat. Fund., São Paulo, 16(4), 515-517, dez. 2013

\title{
Editorial
}

\section{A Psicopatologia Fundamental no mundo: qualidade e difusão}

Os processos de produção científica e de difusão da Psicopatologia Fundamental, tendo começado com o Prof. Dr. Pierre Fédida, psicanalista da Association Psychanalytique de France (APF) e da Université de Paris 7 - Denis Diderot, foram transferidos, em 1995, para o Brasil, com a criação do Laboratório de Psicopatologia Fundamental do Programa de Estudos Pós-Graduados em Psicologia Clínica da Pontifícia Universidade Católica de São Paulo (PUC-SP).

A partir daí, a Psicopatologia Fundamental apresentou um contínuo processo de produção científica e de difusão.

Em 1996, foi criada a Rede Universitária de Pesquisa em Psicopatologia Fundamental, que se transformou, em maio de 2002, na Associação Universitária de Pesquisa em Psicopatologia Fundamental. Esta sociedade científica internacional possui, hoje, 66 membros, professores doutores de 26 universidades brasileiras e de universidades da Argentina, do Chile, da Colômbia, da França, do México, de Portugal e do Reino Unido.

Em março de 1998, foi lançada a Revista Latinoamericana de Psicopatologia Fundamental (RLPF), órgão oficial trimestral impresso e on line, da Associação Universitária de Pesquisa em Psicopatologia Fundamental. Tendo publicado 67 números, a RLPF é, hoje, um importante periódico científico dedicando-se à publicação 
de editorial, artigos originais e resenhas de livros de psicopatologia que levam em consideração a subjetividade. Além disso, publica ensaios raros e de difícil acesso e que são documentos históricos de relevância para outras pesquisas. Valoriza artigos e ensaios resultantes de pesquisas utilizando o método clínico baseado em relato de caso contendo questão a ser investigada.

Em 2013, o Qualis da Fundação Campanha de Aperfeiçoamento do Pessoal do Ensino Superior (CAPES) apresentou a seguinte avaliação da RLPF:

1415-4714 Revista Latinoamericana de Psicopatologia Fundamental (Impresso) A2 PLANEJAMENTO URBANO E REGIONAL /DEMOGRAFIA

1415-4714 Revista Latinoamericana de Psicopatologia Fundamental (Impresso) A2 PSICOLOGIA

1415-4714 Revista Latinoamericana de Psicopatologia Fundamental (Impresso) B1 ARTES / MÚSICA

1415-4714 Revista Latinoamericana de Psicopatologia Fundamental (Impresso) B1 ENFERMAGEM

1415-4714 Revista Latinoamericana de Psicopatologia Fundamental (Impresso) B1 HISTÓRIA

1415-4714 Revista Latinoamericana de Psicopatologia Fundamental (Impresso) B1 INTERDISCIPLINAR

1415-4714 Revista Latinoamericana de Psicopatologia Fundamental (Impresso) B1 SOCIOLOGIA

1415-4714 Revista Latinoamericana de Psicopatologia Fundamental (Impresso) B2 LETRAS / LINGUÍSTICA

1415-4714 Revista Latinoamericana de Psicopatologia Fundamental (Impresso) B3 CIÊNCIA POLÍTICA E RELAÇÕES INTERNACIONAIS

1415-4714 Revista Latinoamericana de Psicopatologia Fundamental (Impresso) B3 EDUCAÇÃO FÍSICA

1415-4714 Revista Latinoamericana de Psicopatologia Fundamental (Impresso) B3 FILOSOFIA/TEOLOGIA

1415-4714 Revista Latinoamericana de Psicopatologia Fundamental (Impresso) B3 MEDICINA III

1415-4714 Revista Latinoamericana de Psicopatologia Fundamental (Impresso) B3 SAÚDE COLETIVA

1415-4714 Revista Latinoamericana de Psicopatologia Fundamental (Impresso) B4 ANTROPOLOGIA / ARQUEOLOGIA

1415-4714 Revista Latinoamericana de Psicopatologia Fundamental (Impresso) B4 CIÊNCIAS SOCIAIS APLICADAS I

1415-4714 Revista Latinoamericana de Psicopatologia Fundamental (Impresso) B4 MEDICINA I 
1415-4714 Revista Latinoamericana de Psicopatologia Fundamental (Impresso) B4 MEDICINA II

1415-4714 Revista Latinoamericana de Psicopatologia Fundamental (Impresso) C ASTRONOMIA/FÍSICA

1415-4714 Revista Latinoamericana de Psicopatologia Fundamental (Impresso) C FILOSOFIA/TEOLOGIA:subcomissão FILOSOFIA

Como se pode observar, a RLPF possui uma ampla penetração em diversas áreas do saber e é considerada, por muitas, como de excelente qualidade.

Além disso, hoje ela está indexada em numerosas bases de dados internacionais importantes como a Thomson Reuters, SciELO, SCOPUS etc.

Em 2004, foram criados os portais do Laboratório de Psicopatologia Fundamental www.psicopatologiafundamental.org e o da Associação Universitária de Pesquisa em Psicopatologia Fundamental www.fundamentalpsychopathology.org que, juntos, são visitados por cerca de 63.000 consulentes por mês, de todo o mundo.

O portal do Laboratório de Psicopatologia Fundamental contém praticamente todas as dissertações e teses defendidas aí. O portal da AUPPF contém a revista e outros importantes textos.

Em 2010, foi criada a Newsletter da AUPPF, publicada mensalmente e enviada para cerca de 50.000 endereços que compõem a mala direta da Associação.

Finalmente, em 2013, foi colocada na www a Plataforma de Psicopatologia Fundamental que reúne concentradamente informações existentes no Google sobre a psicopatologia www.psicopatologiafundamental.org/plataforma/

A Psicopatologia Fundamental combina, dessa forma, a produção científica e a difusão dessa produção e a Revista Latinoamericana de Psicopatologia Fundamental é um importante instrumento científico deste centro. 